\title{
Effect of shape of opening on the stability of caverns: An experimental analysis
}

\author{
NR Thote \\ Visvesvaraya National Institute of Technology \\ Nagpur, India \\ thote1999@gmail.com
}

\author{
Wajid Sohail \\ Larsen \& Toubro \\ Chennai, India
}

\author{
M.R. Saharan \\ CIMFR \\ Nagpur, India
}

\begin{abstract}
Sustainable development requirements made it necessary that underground space shall be used with larger size openings. This is to ensure a greater transportation demand and for preserving environment quality. The need for underground space technology has increased significantly during the past few decades in India. The deep mining and civil engineering applications need to perform rock stability analysis during the excavations. These analysis are closely related with stresses and deformations in the excavation contours. Five key parameters required for stability analysis of any underground excavation are namely; a) in-situ state of stress, b) induced stress fields, c) shape of the opening, d) size of the opening and e) related allowable deformation when the openings are made. The study is focused on changes in the stress regime of a cavern in elasto-plastic rock mass and its impact on the stability. Four different shapes of caverns are considered to study the behavior of the shapes in a particular ground conditions. Commercial numerical code RS3 has been used for the analyses of the problem. Full 3D numerical model has been developed for the analysis. The effect of parallel openings on the stability is also analyzed. An optimum shape for the underground opening is suggested based on the study under the particular rock mass condition.
\end{abstract}

Keywords-stability of opening; stress analysis; shapes of openings, in situ stresses

\section{INTRODUCTION}

Underground construction has become an essential part nowadays. Underground structures such as subways and railways, material storage caverns, highways, sewage and water transport have become an integral part of the infrastructure of today's society. Sustainable development of urban areas requires increasingly large use underground facilities, especially to ensure a greater transportation demand and for preserving the environmental quality. Cavern can be both natural and man-made. Cavern form naturally by the weathering of rock and often extend deep underground. Natural Caverns are formed by various geologic processes and can be of variable sizes. These may involve a combination of chemical processes, erosion from water, tectonic forces, micro-organisms, pressure, and atmospheric influences. Man-made cavern are created by mechanized excavation technique or drill and blast method (Fig. 1).

The stability of the underground excavations is the major issue which is affected by its shape, size of opening, in situ stress, soil conditions etc. Even though the shape of the opening mainly depends on the purpose for which it is to be used, the safe design and construction of an underground opening requires the knowledge of the stress distribution and the displacements that occurs in and around the opening.
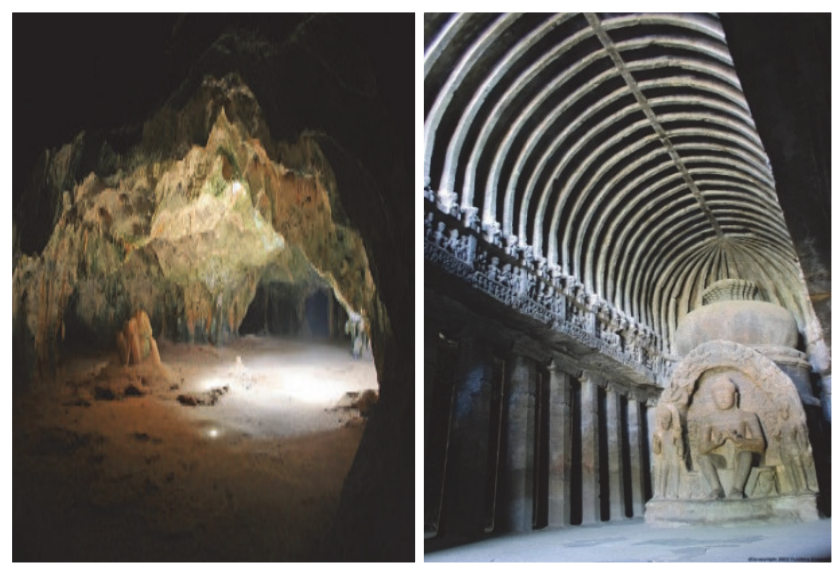

Fig. 1. Natural cavern at Auba and man- made cavern at Ellora

\section{RESEARCH THEME}

The prime objective of the project is to assess the stability of cavern with different shapes, to design the cavern which would be most stable in those conditions and to design a shape which fulfills the need of the underground excavation being carried out.

\section{IN- SITU STRESS IN ROCKS}

In situ stress is an integral part of the theory of rock engineering system [1]. In civil and mining engineering, in situ stresses control the distribution and magnitude of the stresses around underground openings such as tunnels, mines, shaft, caverns [2]. The tunnel engineer has always to consider that the rock medium is subjected to initial stress 
prior to excavation so the final state of stress post excavation in any underground opening is the resultant of the initial state of stress and the stresses induced by excavation. Since induced stresses are directly related to the initial stresses, it is clear that its determination is necessary in any design analysis. The redistributed stresses around the tunnel are termed as induced stresses. Induced stresses thus created affects two simultaneous effects.

In the simple terminology, a bi-axial stress state exists at every excavation face as mentioned earlier. The process is schematically represented in Fig. 2. Two other stresses parallel to the excavation face concentrate at the free face and reduces to the virgin stress values at the same distance ahead from the face (Fig. 2).

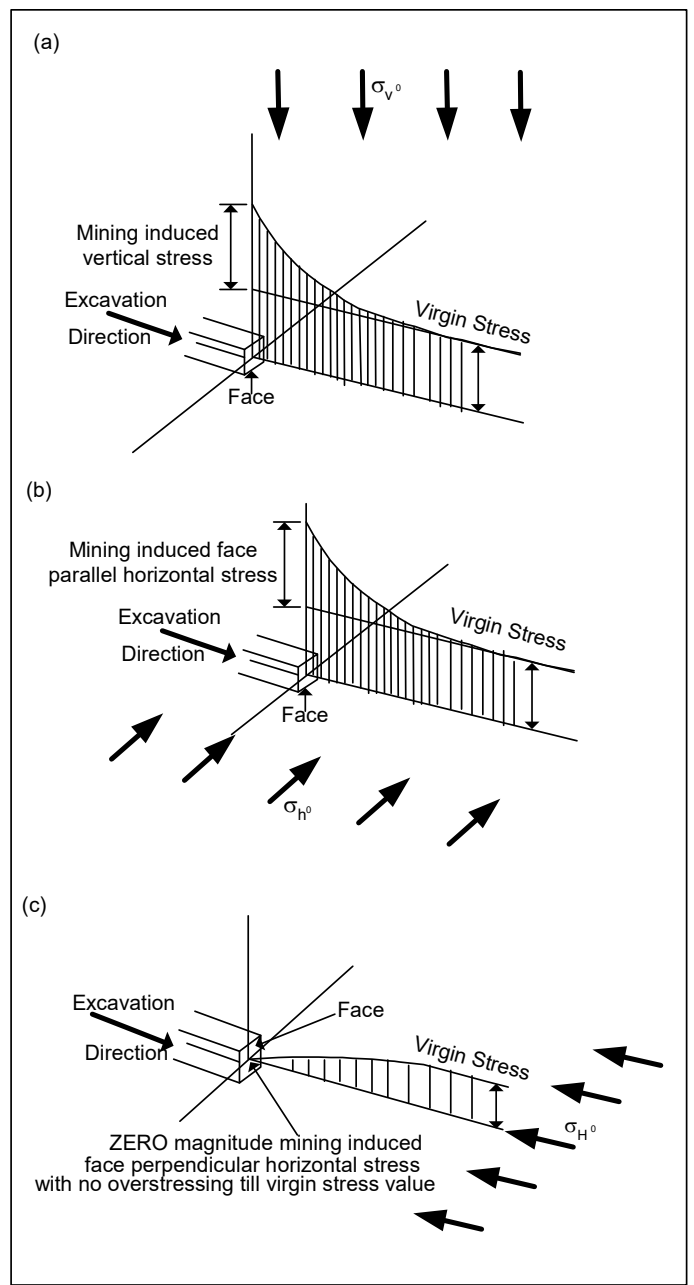

Fig. 2. Virgin and mining induced stresses ahead of an excavation in the center of an advancing face.

\section{STRESS GOVERNED FAILURE AND TUNNELS STABILITY}

Failure of underground openings in hard rock is a function of the in situ stress magnitudes and the characteristics of the rock mass, i.e., the intact rock strength and the fracture network. At low in situ stress magnitudes, the failure process is controlled by the continuity and distribution of the natural fractures in the rock mass.
However, as in situ stress magnitudes increase, the failure process is dominated by new stress-induced fractures growing parallel to the excavation boundary. This fracturing is generally referred to as brittle failure. Initially, at intermediate depths, these failure regions are localized near the tunnel perimeter but at great depth the fracturing envelopes the whole boundary of the excavation (Fig.3a \& b).

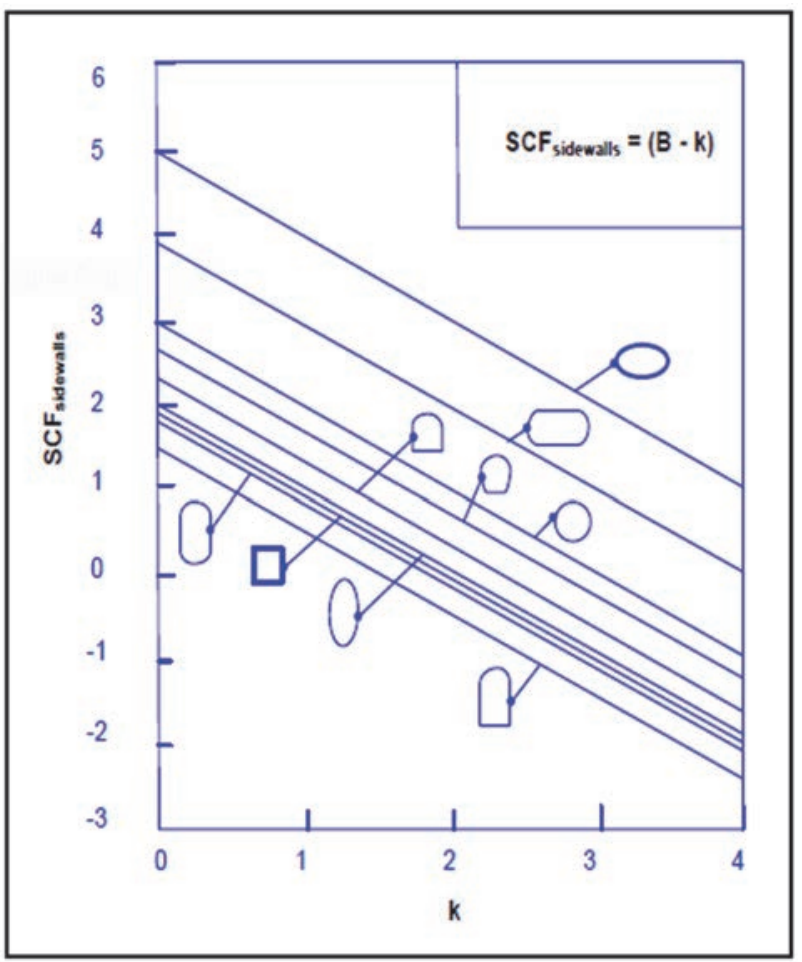

Fig. 3 a. Stress concentration at wall for different

\begin{tabular}{|c|c|c|c|c|c|c|c|c|c||}
\hline \multicolumn{7}{|c||}{ Values of constants A \& B } \\
\hline & 0 & $\square$ & 0 & $\square$ & $\bigcirc$ & $\bigcirc$ & $\bigcirc$ & $\square$ & $\square$ \\
\hline A & 5.0 & 4.0 & 3.9 & 3.2 & 3.1 & 3.0 & 2.0 & 1.9 & 1.8 \\
\hline B & 2.0 & 1.5 & 1.8 & 2.3 & 2.7 & 3.0 & 5.0 & 1.9 & 3.9 \\
\hline
\end{tabular}

Fig 3.b. Values of constant A \& B for different shapes

Squeezing rock mass failure is one of the forms of ductile material failure. Tunnels profiles keeps on reducing under the effect of squeezing rock mass conditions. Another failure type concerned with a tunneling engineer is failure due to creep. Creep is manifested in the form of increasing deformation under constant loading. Evidence shows that the tunnel profile including its lining may fail under low stress due to the effect of creep over the time.

A characteristic of stress-induced failure of tunnels in brittle rock is the notched-shape of the failure region and the associated slabbing and spalling that may occur in a stable manner or violently in the form of strain bursts. These slabs can range in thickness from a few millimeters to tens of centimeters and with large openings can be several square 
meters in surface area $[3,4]$. A review of published case histories where the shape of the slabbing region has been measured and documented shows that the brittle failure process leads to the development of a v-shaped notch, regardless of the original opening shape or size (Fig 4). As shown in Figure the location, extent, and depth of the notch, and hence the support requirements, can vary significantly.

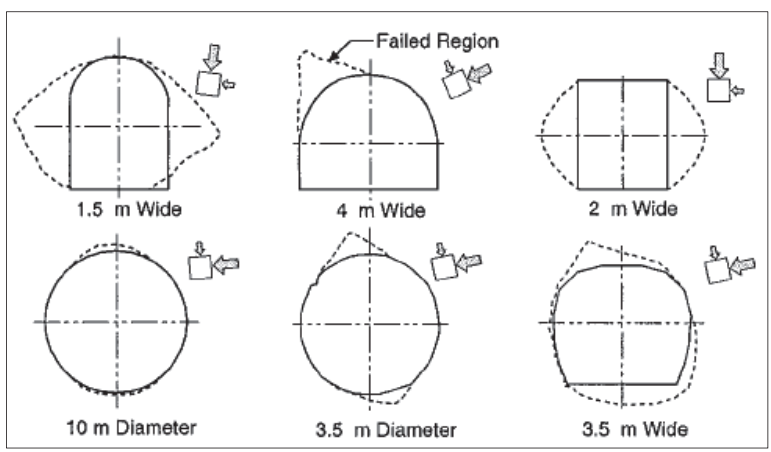

Fig.4. Comparison of the failed (notch) region for tunnels of different size and shape. The orientation of the maximum and minimum in situ stresses, in the plane of the excavation.

\section{DEVELOPMENT OF NUMERICAL MODELS}

Rock mass in numerical modeling is discretized into a large number of individual elements and are analyzed for rock stresses and deformation [5]. Basic Numerical modeling applied in rock mechanics problems are shown in Fig. 5.

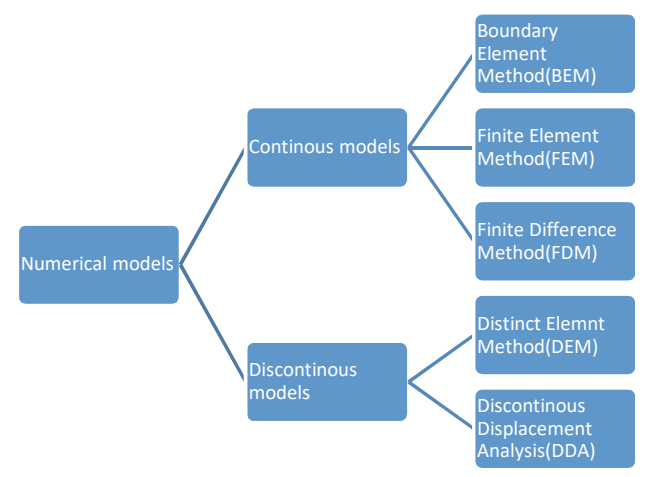

Fig 5. General classification of numerical methods [5]

\section{A) Finite Element Method (RS3)}

It is a numerical technique for finding approximate solutions of partial differential equation as well as integral equations. This approach is based on eliminating the differential equation or rendering the partial differential equations into an approximating system of ordinary differential equation, which are numerically, integrated using standard techniques [7]. This is the most popular method of numerical modeling, which is best suited for solving anisotropic, discontinuous and heterogeneous or non-linear rock masses. It consists of mainly three steps, domain discretization, local approximation, assemblage, and solution of global matrix equation. It involves the representation of continuum as an assembly of elements which are connected at discrete points 'Node'. Problem domain in divided into discrete and displacements for the problem domain. It is the two-dimensional elastic-plastic finite element program for estimating the stress and displacement around the underground openings, and can be used for solving complex geotechnical, rock engineering, mining and civil engineering problems for any time of earth materials.Fig. 5 indicates the inter-relationship between three different modules in RS3 program.

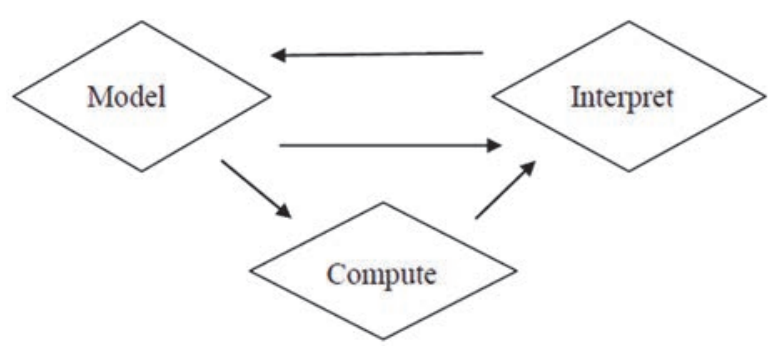

Fig.5. Inter-relationship between three different modules in RS3 program

This program consists of three different independent program modules. Compute and interpret can be started from within the model. In real case, the rock mass is not completely elastic and hence in RS3 it is assumed as elastic plastic material. It can be proved from the computed value of strength factor of rock mass after plastic analysis. Strength factor equal to one after the plastic analysis signifies that the rock mass fails in that particular strength and stresses conditions. If the strength factor is very close to one then it is necessary to provide support system until it increases to a factor of safety that will need for the design of underground opening. During analysis the parameters are taken from the report of CIMFR, 2005 [8]. There are many failure criterions in the options box; all have their own scopes and limitations. Selection of failure criterion is depends upon the available input parameters, type of rock masses, accuracy, and scopes of each criterion. MohrCoulomb failure criterion is best suited for more cohesive rock mass which requires the input parameter such as cohesion, friction angle, tensile strength and dilation parameter which is used in this analysis.

\section{B) Investigation on Effect of Various shapes of Openings}

For the analysis of the opening cavern four different shapes were considered for single opening and parallel opening. The shapes considered for cavern openings are:

1. basket shape,

2. circular shape,

3. horse shoe shape, and

4. rectangular shape

The different shapes considered in this study are shown in Table I and, Figs. 6,7,8 and 9.

TABLE I. DiMENSIONS OF SHAPE CONSIDERED FOR ANALYSIS

\begin{tabular}{|l|c|c|}
\hline Shape & Width/Diameter (m) & Height/Diameter (m) \\
\hline Basket & 16 & 22 \\
\hline Circular & 15 & 15 \\
\hline Horse shoe & 10 & 20 \\
\hline Rectangular & 10 & 20 \\
\hline
\end{tabular}




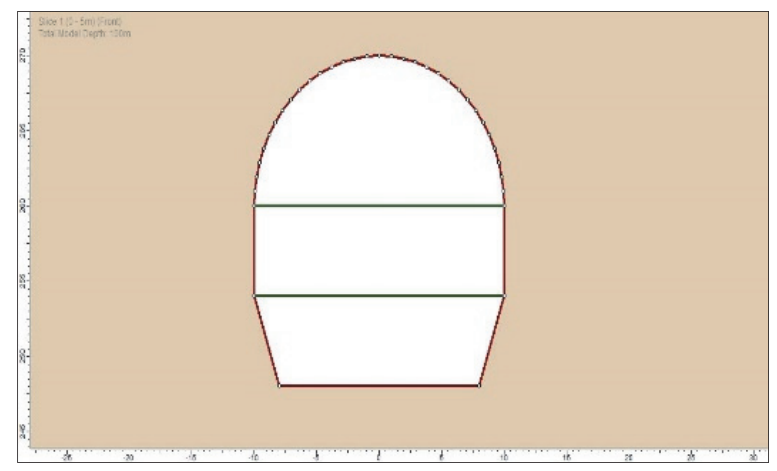

Fig. 6. Basket shape single opening

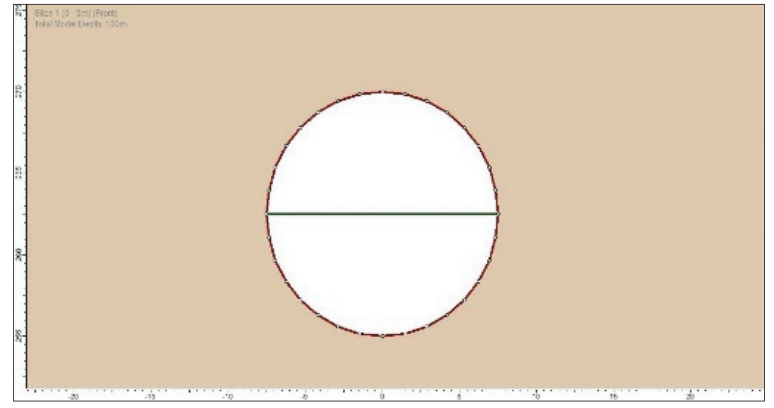

Fig. 7. Circular shaped single opening

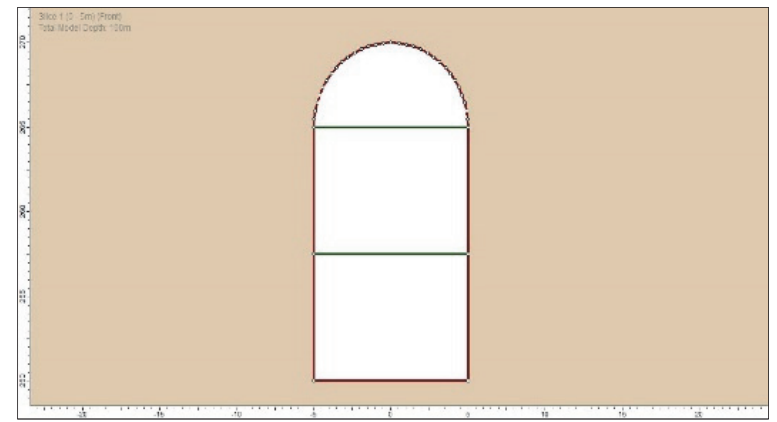

Fig. 8. Horse shoe shaped single opening

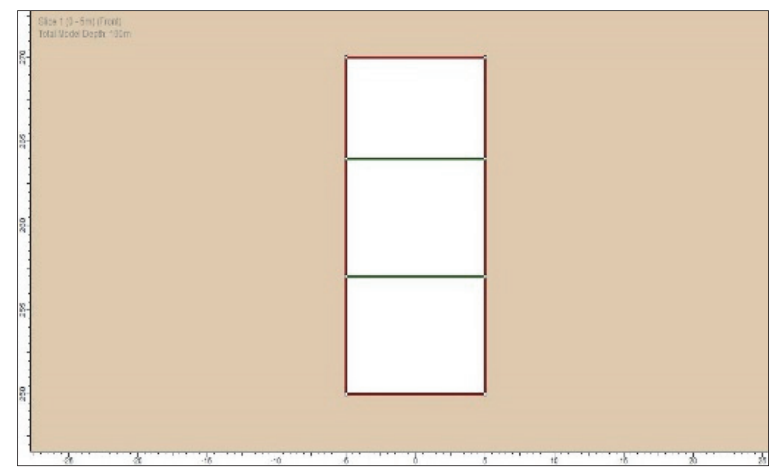

Fig 9. Rectangular shaped single opening

\section{C)Input Parameters for the Analysis}

Material input parameter describes the properties of rock mass. They are needed for stability analysis of any type of underground structure. Some analytical and empirical approaches are used to determine the material input parameters, which are calculated from those empirical and analytical approaches, would be input parameters for the GSI calculator or for Roc data software. GSI calculator and Roc data software are the tools that have direct linked to the RS3 program. It is also possible for manual input of all parameters based on suitable criterion. Material input parameters for the analysis here are taken from CIMFR, 2005[8]. Since the modeling done is without considering any joint set Mohr-Coulomb failure criteria is used.

TABLE II. INPUT PARAMETERS OF ROCK MASS PROPERTIES FOR NUMERICAL MODELING [8]

\begin{tabular}{|l|l|l|}
\hline \multicolumn{1}{|c|}{ Parameter } & $\begin{array}{c}\text { Measured Rock } \\
\text { Property }\end{array}$ & $\begin{array}{c}\text { Rock Mass } \\
\text { Property Used in } \\
\text { Numerical Models }\end{array}$ \\
\hline Elastic Modulus $(\mathrm{GPa})$ & 78 & 56 \\
\hline Poisson's ratio & 0.22 & 0.22 \\
\hline Density, $\left(\mathrm{kg} / \mathrm{m}^{3}\right)$ & 2877 & 2650 \\
\hline Compressive Strength, $(\mathrm{MPa})$ & 100 & 33.29 \\
\hline Tensile Strength, $(\mathrm{MPa})$ & 10 & 4.43 \\
\hline Vertical stress $\left(\sigma_{\mathrm{v}}\right), \mathrm{MPa}$ & 4.6375 & 4.6375 \\
\hline Major hor. stress $\left(\sigma_{\mathrm{H}}\right), \mathrm{MPa}$ & 18.453 & 18.453 \\
\hline Minor Hor. stress $\left(\sigma_{\mathrm{h}}\right), \mathrm{MPa}$ & 15.11 & 15.11 \\
\hline Cohesion $(\mathrm{c}), \mathrm{MPa}$ & 5 & 5 \\
\hline $\begin{array}{l}\text { Angle of Internal Friction } \\
\left(\varphi_{\mathrm{r}}\right), \text { deg. }\end{array}$ & $55^{0}$ & $55^{0}$ \\
\hline
\end{tabular}

\section{RESULTS AND DISCUSSION}

Models were run on RS3 for various shapes of the underground opening were compiled and a comparison was made as discussed below.

- Stress change for each shape on the center of crown.

- $\quad$ Stress change for each shape on the center of sidewalls.

- Displacement change for each shape on center of crown.

- Displacement change for each shape on the center of sidewalls.

- Strength factors change each shape on the center crown.

- Strength factor change for each shape on the center of sidewall.

The analysis was done for the various conditions as:

- Elastic condition at face.

- Elasto-Plastic condition at face.

- Elastic condition $50 \mathrm{~m}$ behind the face.

- Elasto-Plastic condition $50 \mathrm{~m}$ behind the face

Fig 10a,b,c indicates sample results of total displacement and strength factor at crown of face and at 50 $m$ advance for single opening for elastic conditions. Higher stresses are induced at the crown as horizontal stress is more than the vertical stresses which is the condition used in the analysis. No displacement is observed at the face of the opening and exceptionally low deformation is observed at $50 \mathrm{~m}$ advance. Strength Factor is more at the face of the 
opening than at $50 \mathrm{~m}$ advance. All the values are seen trending to its in situ conditions.

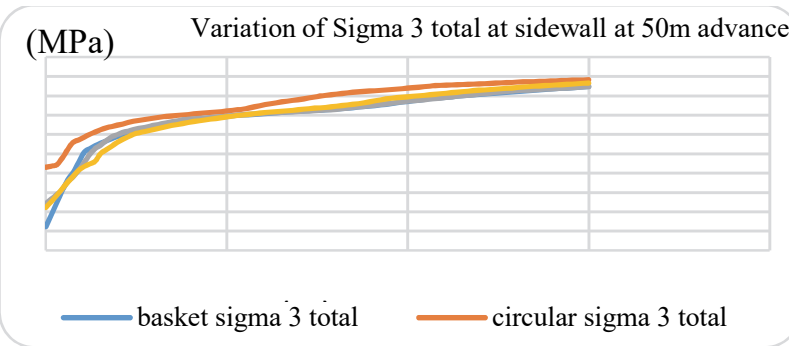

(MPa) Variation of Sigma 1 total at sidewall at 50m advance

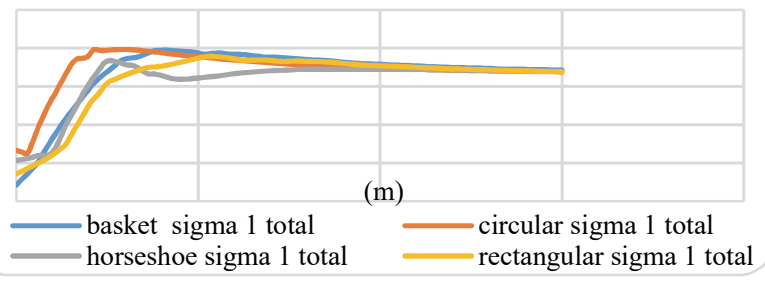

(m)

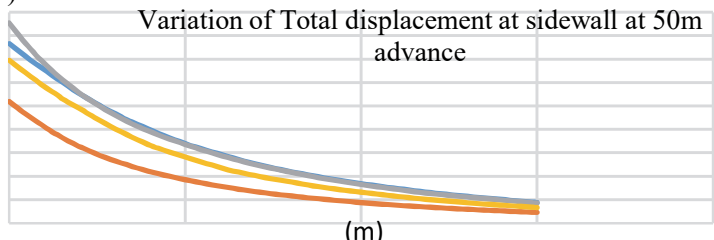

basket total displacement

circular total displacement

Fig. 10a, b \& c Variation of Sigma 1 total, Sigma 3 total, total displacement and strength factor at the sidewall at $50 \mathrm{~m}$ advance for Parallel opening (Elasto-plastic condition)

\section{CONCLUSIONS}

Numerical analysis of four shapes of the underground opening where done using RS3 for Single and parallel opening for Elastic and Elasto-plastic condition at face and at $50 \mathrm{~m}$ advance from the face. Variation of Sigma 1 total, Sigma 3 total, Total displacement and Strength factor were studied for every conditions.

Results presented in the study, particularly Strength Factor contouring, presents all safe design for all the cavern shapes. The major results of the work are as follows:

- The behavior of all the shapes is almost similar in the ground conditions and not any significant differences in any shape is seen except for variation of sigma 3 total at face of the sidewall and also at crown at $50 \mathrm{~m}$ advance for both single and parallel opening .

- Compared to all the shapes Circular shape behavior was found to be the best amongst all followed by Basket, Horse shoe, and Rectangular.

- The behavior of Basket and Circular shape have been is almost identical in most of the conditions

- Considering the behavior of various shapes basket shape can be chosen as the most optimum shape of the opening because it provides a working platform and the behavior of it is better than the horseshoe shape. In case of a bigcircular opening it is very difficult to construct due to precise drilling is not possible at the site.

\section{REFERENCES}

[1] J.A.Hudson, "Engineering rock mechanics"(eds) Elsevier Science Ltd., 1997

[2] E. Hoek and E.T. Brown, "Underground excavations in rock". Chapman \& Hall, London, 1980.

[3] E.T. Brown and E. Hoek, "Trends in relation-ships between measured rock in situ stresses and depth," Int. J. Rock Mech. Min. Sci. \& Geomech. Abstr. Vol.15, 1978.

[4] P.R. Sheorey, "A theory for in situ stresses in isotropic and transversely isotropic rock," Int. J. Rock Mech. Min. Sci. \&Geomech. Abstr. Vol. 31, no.1, 1994.

[5] B. Nilsen and A. Palmstrøm, "Engineering geology and rock engineering",Handbook No 2. Oslo: Norwegian Group for Rock Mechanics (NBG).p. 249,2000.

[6] A. Palmstorm, "A method to estimate tangential stresses around underground openings", Appendix-9,Phd thesis, Oslo University, Norway, 1995.

[7] RS31.0.ReferenceManual.ocscienceInc.http://www.rocscience.com.

[8] CIMFR " Impact of In-Situ Stress Regime on Proposed Caverns Shapes For SALPG”, Research Report (Visakhapatnam Project), 2005.

[9] N. Hast, "The measurement of rock pressure in mines", Sver. Geol. Under. Ser. C. vol. 52, pp 1-152, 1958. . 